CLNESP-D-15-00009R4

\title{
PATIENTS WITH DYSLIPIDEMIA ON A SELF-REPORTED DIET HAVE A HEALTHIER DIETARY INTAKE THAN THE GENERAL POPULATION. THE COLAUS STUDY
}

Running title: composition of hypolipidemic diets

$$
\begin{aligned}
& \text { Pedro Marques-Vidal, MD, } \mathrm{PhD}^{1} \text {; Peter Vollenweider, MD }{ }^{1} \text {; Matthieu Grange, Student }{ }^{1} \text {; Idris } \\
& \text { Guessous, } \mathrm{MD}, \mathrm{PhD}^{2,3} \text { and Gérard Waeber, MD }{ }^{1}
\end{aligned}
$$

${ }^{1}$ Department of Internal Medicine, Internal Medicine, Lausanne University Hospital, Lausanne, Switzerland; ${ }^{2}$ Institute of Social and Preventive Medicine (IUMSP), Lausanne University Hospital, Biopôle 2, Route de la Corniche 10, 1010 Lausanne, Switzerland; ${ }^{3}$ Unit of Population Epidemiology, Division of primary care medicine, Department of Community Medicine, Primary Care and Emergency Medicine, Geneva University Hospitals, Switzerland

\section{ABSTRACT}

Background \& aims: dietary measures complement hypolipidemic drug treatment, but little is known regarding the nutritional content of reported hypolipidemic diets in the general population. Thus, we 
characterized the dietary intake of subjects aged 40 to 80 years according to awareness of dyslipidemia and presence of a hypolipidemic diet.

Methods: cross-sectional study conducted between 2009 and 2012 on 4289 participants (2274 women) living in Lausanne, Switzerland; 1370 (32\%) reported a diagnosis of dyslipidemia, of whom 242 (18\%) reported a hypolipidemic diet. Dietary intake was assessed using a validated food frequency questionnaire.

Results: compared to participants aware of dyslipidemia not on a diet, those on a diet consumed significantly more fruits (mean \pm standard deviation: $2.5 \pm 1.9$ vs. $1.9 \pm 1.7$ portions/day), vegetables $(1.6 \pm 1.0$ vs. $1.4 \pm 0.9$ portions/day) and fish ( $1.9 \pm 1.4$ vs. $1.6 \pm 1.1$ portions/week) and less meat $(4.5 \pm 2.7$ vs. $5.2 \pm 2.9$ portions/week). They also had a significantly higher intake of total carbohydrates (50.1 \pm 8.6 vs. $47.1 \pm 8.3 \%$ of total energy intake - TEI), monounsaturated (39.9 \pm 5.4 vs. $39.4 \pm 4.3 \%$ total fat) and polyunsaturated

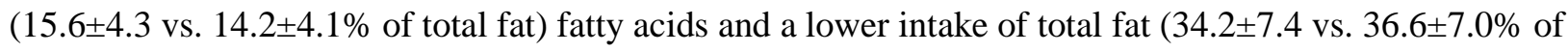
TEI) and saturated fatty acids (35.1 \pm 6.2 vs. $37.8 \pm 5.7 \%$ of total fat). Participants aware and on a diet met more nutritional recommendations of the Swiss Society of Nutrition $(2.1 \pm 1.0$ vs. $1.7 \pm 0.9, \mathrm{p}<0.001)$ than participants not on a diet.

Conclusion: when implemented, hypolipidemic diets lead to a healthier dietary intake than in the general population.

Keywords: dyslipidemia; dietary composition; nutritional recommendations; cross-sectional study; Switzerland. 


\section{Introduction}

Cardiovascular disease (CVD) is the main cause of premature death worldwide, with a considerable health and economic burden [1]. Several studies have shown that a healthy diet improves lipids independently of lipid medication [2,3]. Still, only a limited percentage of patients with dyslipidemia actually comply with dietary guidelines [4]. Several reasons for noncompliance have been identified among patients, namely lack of conviction regarding the efficiency of the diet, lack of motivation to change ones diet, belief that one's diet is already adequate, difficulties in conciliating diet with family life and taking hypolipidemic drugs $[4,5]$. Indeed, a recent study conducted in the USA suggested that the quality of dietary intake has decreased among patients on statins, with an increased caloric and fat intake among statin users compared to nonusers [6]. Similarly, the non-provision of dietary counselling by doctors could be related to lack of time, difficulty in implementation and underestimation of the importance of cholesterol management [7-9].

Switzerland is a small European country characterized by a low mortality from CVD. We have previously shown that compliance with dietary recommendations in the general population was low [10, 11], but to our knowledge no information existed regarding dietary intake and/or compliance with dietary recommendations of patients aware of dyslipidemia. Thus, we aimed to characterize the dietary intake of subjects aged 40 to 80 years according to awareness of dyslipidemia and presence or absence of a hypolipidemic diet.

\section{Materials and methods}

\section{Participants}

The rationale, sampling and follow-up procedures of the CoLaus study have been described previously $[12,13]$. Briefly, the complete list of Lausanne inhabitants aged 35 to 75 years $(n=56,694)$ was provided by the population registry of the city. Lausanne is a multicultural city with $40 \%$ non-Swiss residents [14] and $80 \%$ French speakers [15]. A simple, nonstratified random sample of $35 \%$ of the overall population was drawn. The following inclusion criteria were applied: (a) age 35-75 years and (b) 
willingness to take part in the examination and to donate blood samples. Recruitment began in June 2003 and ended in May 2006. Participation rate was $41 \%$.

The first follow-up took place between April 2009 and September 2012 and included all participants of the baseline study willing to participate to the follow-up [13], corresponding to $75 \%$ of the initial baseline sample. We only consider data from the follow-up examination as dietary intake assessment was first introduced here.

\section{Dietary intake}

Dietary intake was assessed using a self-administered, validated semi quantitative Food Frequency Questionnaire (FFQ) which also included portion size $[16,17]$. This FFQ assesses the dietary intake during the previous 4 weeks of 97 different food items which account for more than $90 \%$ of the intake of calories, proteins, fat, carbohydrates, alcohol, cholesterol, vitamin D and retinol, and $85 \%$ of fibers, carotene and iron. For each item, consumption frequencies ranging from "less than once during the last 4 weeks" to " 2 or more times per day" were provided. Participants were also asked to indicate the average serving size (smaller, equal or bigger) compared to a reference size. The FFQ was checked for completion by trained interviewers the day of the visit. To our knowledge, there is no FFQ (validated or not) assessing dietary intake for the whole year in Switzerland; the other available and validated FFQ also assesses the dietary intake of the previous month [18]. Hence, this FFQ provides the best dietary assessment currently available.

Reported food consumption frequencies were converted into daily or weekly consumptions as follows: "never these last 4 weeks" =0; "once/month" =1/28; "2-3/month" =2.5/28; "1-2/week" =1.5/7; "3-4 times/week" = 3.5/7; "once/day" $=1$ and " $2+/$ day" $=2.5$. The frequency of consumption of one food category was obtained by summing up all consumption frequencies of the foods in that category.

Conversion into nutrients was performed base on the French CIQUAL food composition table. Two values for total energy intake (TEI) were computed: one including alcohol consumption, the other not. Total protein, carbohydrate and fat were expressed as percentage of TEI (alcohol excluded). Animal 
protein was expressed as percentage of total protein; simple sugars (disaccharides) were expressed as percentage of total carbohydrates; saturated (SFA), mono- (MUFA) and polyunsaturated (PUFA) fatty acids were expressed as percentage of total fat.

Compliance with the dietary recommendations of the Swiss Society of Nutrition [19-21] was computed as previously [10]. These recommendations are in agreement with food-based guidelines of other countries and have also been officially endorsed by the Swiss government [19, 21]. The recommendations regarding food intake are: $\geq 2$ fruit portions/day; $\geq 3$ vegetable portions per day; $\leq 5$ portions meat per week; $\geq 1$ portion fish per week and $\geq 3$ portions dairy products per day. Compliance with the recommendation for fish was assessed in two ways: considering all types of fish (including fried and canned), or fresh fish only. Regarding nutrient intake, only the following recommendations were considered: total fat <30\% TEI; SFA <10\% TEI; MUFA >10\% TEI; PUFA $>10 \%$ TEI; cholesterol<300 mg/day and Fiber $>30 \mathrm{~g} /$ day [19]. Alcohol consumption was considered as acceptable if $<20 \mathrm{~g} /$ day for men and $<10 \mathrm{~g} /$ day for women [22]. For each recommendation, a binary variable ( $1=$ yes, $0=$ no) was computed, and the total number of recommendations complied to was summed up.

\section{Other methods}

All participants attended the outpatient clinic of the University Hospital of Lausanne in the morning after an overnight fast. Participants were seen during a single visit which included an interview, a physical assessment, and blood and urine collections in the fasting state. Data were collected by trained field interviewers in a single visit lasting about $60 \mathrm{~min}$. Participants attending the examination were apparently free from an acute disease. If they presented an acute disease, another examination was scheduled. Participants had to restrain from heavy exercise and to maintain their usual diet the day before testing. Participants were asked regarding their personal and family history of disease. Medicines (either self-prescribed or prescribed by a doctor) were identified by requesting participants to bring all the medicines they were currently taking to the visit. 
Nationality was categorized into Swiss and the four most frequent nationalities (providing at least 100 participants): French, Italian, Portuguese and Spanish; the other 20+ nationalities were grouped together as the number of participants for each nationality was small.

Diagnosis of dyslipidemia was defined by a positive answer to the question "Have you ever been told that your cholesterol level was too high (hypercholesterolemia)“. Presence of diet against dyslipidemia was defined as a positive answer to the question "are you currently on a low fat diet / diet against cholesterol?". No information was collected whether the diet was self- of doctor-prescribed or regarding noncompliance with a previously prescribed diet. Hypolipidemic drug treatment was assessed by asking the participants to bring all self- or doctor-prescribed medicines currently taken. Diagnosis of diabetes was defined by a positive answer to the question "Have you ever been told that you had diabetes?". As management of diabetes includes dietary recommendations [23, 24], it was expected that participants with diabetes would have a higher likelihood of receiving dietary counselling and thus to have a healthier diet than participants without diabetes.

Body weight and height were measured with participants standing barefoot and in light indoor clothes. Body weight was measured in kilograms to the nearest $100 \mathrm{~g}$ using a Seca ${ }^{\circledR}$ scale, which was calibrated regularly. Height was measured to the nearest $5 \mathrm{~mm}$ using a Seca ${ }^{\circledR}$ height gauge. Overweight was defined as a body mass index (BMI) $\geq 25$ and $<30 \mathrm{~kg} / \mathrm{m}^{2}$; obesity was defined as a BMI $\geq 30 \mathrm{~kg} / \mathrm{m}^{2}$.

\section{Exclusion criteria}

Participants were excluded from the main analysis if their total energy intake was less than 850 or over $4500 \mathrm{kcal} / \mathrm{day}$ [25] or if they had no data regarding dietary intake or any other variable used in the analysis. Sensitivity analysis was conducted including all participants with available dietary intake, irrespective of the total energy intake.

\section{Statistical analysis}

Statistical analyses were performed using Stata version 13.1 for windows (Stata Corp, College Station, Texas, USA). Descriptive results were expressed as number of participants (percentage) or as 
average \pm standard deviation. Bivariate analyses were performed using chi-square or Fisher's exact test for qualitative variables and oneway analysis of variance (ANOVA) or Kruskall-Wallis test for quantitative variables. Multivariate analysis was performed using ANOVA and logistic regression. For ANOVA, posthoc pairwise comparisons were performed using Scheffe's method. Among participants diagnosed with dyslipidemia, the associations of hypolipidemic drug with dietary intake were assessed by testing an interaction term between self-reported lipid-conscious diet and hypolipidemic drug treatment. For logistic regression, the results were expressed as multivariable-adjusted Odds ratio (OR) and 95\% confidence interval (CI). Statistical significance was assessed for $\mathrm{p}<0.05$.

\section{Ethical statement}

The CoLaus Study was approved by the Institutional Ethics Committee of the University of Lausanne and all participants provided written informed consent prior to being examined.

\section{Results}

\section{Characteristics of participants}

Of the initial 5064 participants in the first follow-up, 267 (5.3\%) were excluded because of improbable total energy intake, and a further 508 (10\%) because of missing data, leaving 4289 participants (84.7\%) for analysis. Comparison of the characteristics between participants included and excluded from the main analysis is summarized in supplementary table 1. Excluded participants were older, lived less frequently in couple, had a lower educational level, were more frequently smokers, obese and with a personal history of diabetes than included participants. Excluded participants also reported less frequently a diet against dyslipidemia (supplementary table 1).

Among the 4289 participants included in the analysis, 68\% reported no diagnosis of dyslipidemia, $21 \%$ reported a diagnosis but no dietary management of dyslipidemia, and $11 \%$ reported a diagnosis and dietary management of dyslipidemia. The characteristics of the participants according to diagnosis of dyslipidemia and self-reported diet against dyslipidemia are summarized in table 1. Participants diagnosed with dyslipidemia were older, had a lower educational level, were more frequently former smokers, had 
more frequently a personal history of CVD or diabetes and were more frequently overweight and obese than participants not diagnosed with dyslipidemia (table 1). Participants diagnosed with dyslipidemia on a diet were more frequently women, while participants diagnosed but not on a diet were less frequently women than participants not diagnosed with dyslipidemia (table 1).

\section{Dietary intake}

Dietary intake according to diagnosis of dyslipidemia or self-reported diet against dyslipidemia is summarized in table 2. Participants diagnosed with dyslipidemia and on a diet had a higher reported intake of fruits and fish, and a lower reported intake of meat than participants not diagnosed with dyslipidemia. Participants diagnosed with dyslipidemia and not on a diet had a higher reported intake of meat and a lower reported intake of vegetables than participants not diagnosed with dyslipidemia (table 2).

Participants diagnosed with dyslipidemia and on a diet had a higher consumption of carbohydrates, MUFA, PUFA and fiber, and a lower consumption of total fat, SFA and cholesterol than participants not diagnosed with dyslipidemia. Participants diagnosed with dyslipidemia and not on a diet had a similar nutrient intake than participants not diagnosed with dyslipidemia and had higher alcohol consumption than the others (table 2).

Similar findings were obtained when the analysis was stratified by gender (supplementary tables 2 and 3) or when all participants with available dietary intake were included (supplementary table 4), except that some associations were no longer significant, such as fiber and alcohol intake in women.

\section{Compliance with recommendations}

Compliance with the recommendations of the Swiss society of nutrition according to diagnosis of dyslipidemia or self-reported diet against dyslipidemia is summarized in table 3 .

Regarding recommendations for foods, participants diagnosed with dyslipidemia and on a diet had higher odds of meeting the recommendations for fruit and fish intake than participants not diagnosed with dyslipidemia. Participants diagnosed with dyslipidemia and not on a diet had lower odds of meeting the 
recommendations for fruit and vegetable intake than participants not diagnosed with dyslipidemia (table 3). Among participants diagnosed with dyslipidemia, presence of a diet was associated with higher odds of meeting at least 3 recommendations, while absence of diet was associated with lower odds of meeting the recommendations (table 3).

Regarding recommendations for nutrients, participants diagnosed with dyslipidemia and on a diet had higher odds of meeting the recommendations for total fat, SFA and cholesterol, and lower odds of meeting the recommendation for MUFA than participants not diagnosed with dyslipidemia. No differences regarding compliance for PUFA and fibre were found between participants diagnosed and not on a diet and participants not aware of being dyslipidemic (table 3). Finally, participants diagnosed and not on a diet had lower odds of meeting alcohol recommendations (table 3).

Similar findings were obtained when the analysis was stratified by gender (supplementary tables 5 and 6) or when all participants with available dietary intake were included (supplementary table 7), except that some associations were no longer significant, such as moderate alcohol consumption in women.

\section{Discussion}

To our knowledge, this is the first study ever conducted in Switzerland and one of the few in Europe assessing the reported dietary intake among patients diagnosed with dyslipidemia, taking into account the presence/absence of a diet. Our results indicate that patients diagnosed with dyslipidemia and on a diet report a healthier dietary intake, while patients diagnosed with dyslipidemia but not on a diet tend to report a less healthy dietary intake than the general population.

\section{Dietary management of dyslipidemia}

Dietary management is a cornerstone of CVD prevention [22] and management of dyslipidemia [26]. A French study conducted in 1998 among 1717 general practitioners reported that almost $96 \%$ of them provided dietary recommendations to patients with dyslipidemia [27]. Studies conducted in patients reported lower levels of dietary management: $88 \%$ in a study conducted in 2003-4 among patients with 
high LDL cholesterol living in New York [28]; a study conducted in 2008-10 in Spain among patients with hypercholesterolemia (total cholesterol $200 \mathrm{mg} / \mathrm{dL}$ or on drug treatment) showed that $89.8 \%$ of then had received dietary advice, but that $15 \%$ of them did not follow it [29]. Another French study assessing dietary compliance among patients reporting a diagnosis of dyslipidemia estimated that only $46 \%$ of them had a good or pretty good compliance [30]. In this study, only one third of patients diagnosed with dyslipidemia reported being on a diet. Although the findings from the current study cannot be directly compared with the results from other studies, still they suggest that advice from health carers and/or compliance by the patients regarding dietary management of dyslipidemia is low in Switzerland. For instance, a French study reported that although $83 \%$ of hypercholesterolemic patients recall they should eat more fish, only $51 \%$ actually do so [4]. It is also possible that people reporting being on a diet reported an intake that better reflected what they had been told to eat than what they actually ate [31]. Other explanations for not meeting dietary recommendations include the belief that oneself diet is already acceptable, unwillingness to restrict one's diet, social difficulties in implementing the recommendations or use of lipid lowering drugs [4]. Factors related to healthcare include lack of time, difficulty in implementation of the recommendations and underestimation of the importance of cholesterol management [7-9].

Overall, our results suggest that there is still room for implementation of dietary management of dyslipidemia among Swiss patients. No information was collected whether the reported diet was selfprescribed or prescribed by a dietician or a doctor. Hence, some of the reported diets might not be optimal neither regarding overall nutritional adequacy, nor in terms of lipid lowering. Further, simple, easy to implement dietary measures have been shown to be effective: a randomized controlled trial showed that a low-intensity dietary counselling provided by primary care physician produced clinically meaningful improvements in both diet and lipids of magnitude similar to changes reported with high intensity interventions [32].

\section{Dietary intake}


Patients diagnosed with dyslipidemia and on a diet reported a higher intake of fruits and fish, and a lower intake of meat than patients not diagnosed with dyslipidemic. These findings are in agreement with the literature, where a diets rich in fruits, omega-3 (i.e. from fish) and low in SFA (one of the main sources being meat) have been shown to protect against coronary heart disease (for a review, see [33]). Still, it was not possible to independently ascertain if participants who reported being on a diet were actually consuming it. Thus, a reporting bias cannot be completely ruled out.

European dietary recommendations to reduce total and LDL cholesterol levels include the reduction of saturated and trans fats and cholesterol intake, and the increase in dietary fibre [26]. The recommendations to reduce triglyceride levels include the reduction of alcohol intake and of mono- and disaccharides, and the replacement of SFA with MUFA or PUFA [26]. Although no information regarding dietary intake of trans fatty acids could be obtained, our results indicate that patients diagnosed with dyslipidemia and on a diet were quite compliant to these recommendations, as they presented a higher consumption of MUFA, PUFA and fibre, and a lower consumption of total fat, SFA and cholesterol than participants not aware of being dyslipidemic. Overall, our results suggest that, in this sample, diets implemented against dyslipidemia meet quite well with the current recommendations. The fact that patients diagnosed with dyslipidemia and on a diet did not have reduced alcohol consumption might be related to the fact that most of them presented with hypercholesterolemia rather than hypertriglyceridemia, but we have no data to confirm this possibility.

\section{Compliance with dietary recommendations}

As for dietary intake, patients diagnosed with dyslipidemia and on a diet had higher odds of meeting most Swiss dietary recommendations. Interestingly, no differences were found regarding compliance with vegetables and meat consumption, a finding also reported elsewhere [34]. The lack of difference regarding vegetable intake might be partly related to the already low compliance levels regarding vegetable intake reported previously [10], while the lack of difference regarding meat intake might be due to changes in the type of meat, i.e. replacing poultry for beef or pig. Indeed, participants 
diagnosed and on a diet consumed less processed meat products and tended to consume less red meat, while the consumption of poultry was similar between groups (supplementary table 8). This might explain the higher compliance with low fat, low SFA and low cholesterol recommendations among participants diagnosed and on a diet relative to the non-diagnosed group.

In a previous study [10], we reported that migrants have a better compliance regarding dietary recommendations than Swiss born participants. Similar findings were observed among participants diagnosed with dyslipidemia (supplementary table 11), and no differences were found between migrants and Swiss nationals regarding the distribution of participants not diagnosed, diagnosed on a diet and diagnosed not on a diet (not shown). Thus, our results suggest that migrants with dyslipidemia have the same or perhaps even a better compliance to dietary recommendations than Swiss nationals.

Overall, our results suggest that, among participants diagnosed with dyslipidemia, reporting a diet is favourably associated with a higher compliance with dietary recommendations.

\section{Study limitations}

This study has several limitations. Firstly, participants differed significantly from excluded ones regarding several characteristics known to influence dietary intake such as age, education and smoking. Still, sensitivity analyses including all participants led to similar findings, suggesting that our results might be applicable to the general population. Secondly, only awareness of dyslipidemia was considered, and it is known that a significant fraction of the population presents with dyslipidemia without being aware of it. Thus, the presence of an attribution bias cannot be excluded, as a non-negligible fraction of the non-aware group consists of dyslipidemic subjects, whose dietary intake might differ from the non-dyslipidemic ones. This bias might increase the difference between participants diagnosed and on a diet and non diagnosed participants. Still, the aim of this study was to assess whether diagnosis of dyslipidemia led to dietary management of the condition, and the associated dietary changes, not the association between dietary intake and presence of dyslipidemia as assessed solely by lipid measurement. Thirdly, several factors that could influence the compliance with a lipid-conscious diet such as severity and type of 
dyslipidemia (i.e. high cholesterol or high triglycerides) were not collected, and it would be of interest that future studies assess the effects of these factors on dietary compliance. Fourthly, the assignment to a diet / non diet group was based on the self-perception of the participants regarding their diet. The perception of the participants could be wrong, or the participants could incorrectly answer positively to the question because of guilt about noncompliance, leading to a reporting bias. Still, this would lead to a decrease in dietary quality and compliance with recommendations; thus, it is possible that the results presented might actually underestimate the quality of the lipid-conscious diet. A sizable fraction of the participants was non-Swiss; hence possible comprehension issues could arise while filling the FFQ. Still, as all participants had already participated in the baseline study and had been faced with large questionnaires in French, we believe that the participants in the second wave of the CoLaus study had an adequate literacy to understand the FFQ. The FFQ only assessed dietary intake from the last 4 weeks, so seasonal variations could not be captured. Still, similar short FFQs have been used in other studies [35]. Finally, the CoLaus study was conducted in an urban setting (Lausanne) and in a French-speaking canton (Vaud); it is thus possible that the results obtained might not be extrapolated to other Swiss cantons or to other countries, due to differences in medical practice. Still, they provide important information regarding the frequency and the characteristics of the dietary management of patients with dyslipidemia, and could serve as reference for comparing the effectiveness of educational campaigns aiming at implementing dietary management of cardiovascular risk factors.

\section{Conclusion}

We conclude that in Switzerland, only half of patients diagnosed with dyslipidemia are on a lipidconscious diet. Presence of a lipid-conscious diet in patients diagnosed with dyslipidemia favourably influences their dietary intake compared to the general population.

\section{Acknowledgements}

Nobody to acknowledge. 


\section{Statement of authorship}

PMV made the statistical analyses and wrote most of the article; MG made most of the literature search, helped in data analysis and wrote part of the article; IG collected data and revised the article for important intellectual content; PV and GW conceived the study and revised the article for important intellectual content.

\section{Funding sources}

The CoLaus study was supported by grants from the Swiss National Science Foundation [grant no: 33CSCO-122661 and FN 33CSC0-139468]; GlaxoSmithKline, and the Faculty of Biology and Medicine of Lausanne, Switzerland. The funding sources had no involvement in study design; in the collection, analysis and interpretation of data; in the writing of the report; and in the decision to submit the article for publication.

\section{References}

[1] Heidenreich PA, Trogdon JG, Khavjou OA, Butler J, Dracup K, Ezekowitz MD, et al. Forecasting the future of cardiovascular disease in the United States: a policy statement from the American Heart Association. Circulation. 2011;123:933-44.

[2] Bouillon K, Singh-Manoux A, Jokela M, Shipley MJ, Batty GD, Brunner EJ, et al. Decline in lowdensity lipoprotein cholesterol concentration: lipid-lowering drugs, diet, or physical activity? Evidence from the Whitehall II study. Heart. 2011;97:923-30.

[3] Lee SP, Dart AM, Walker KZ, O'Dea K, Chin-Dusting JP, Skilton MR. Effect of altering dietary n6:n-3 PUFA ratio on cardiovascular risk measures in patients treated with statins: a pilot study. Br J Nutr. 2012;108:1280-5.

[4] Bruckert E, Pouchain D, Auboiron S, Mulet C. Cross-analysis of dietary prescriptions and adherence in 356 hypercholesterolaemic patients. Archives of cardiovascular diseases. 2012;105:557-65.

[5] Serour M, Alqhenaei H, Al-Saqabi S, Mustafa AR, Ben-Nakhi A. Cultural factors and patients' adherence to lifestyle measures. Br J Gen Pract. 2007;57:291-5. 
[6] Sugiyama T, Tsugawa Y, Tseng CH, Kobayashi Y, Shapiro MF. Different time trends of caloric and fat intake between statin users and nonusers among US adults: gluttony in the time of statins? JAMA Intern Med. 2014;174:1038-45.

[7] Erhardt LR, Hobbs FD. A global survey of physicians' perceptions on cholesterol management: the From The Heart study. Int J Clin Pract. 2007;61:1078-85.

[8] Durack-Bown I, Giral P, d'Ivernois JF, Bazin C, Chadarevian R, Benkritly A, et al. Patients' and physicians' perceptions and experience of hypercholesterolaemia: a qualitative study. Br J Gen Pract. 2003;53:851-7.

[9] Hobbs FD, Erhardt L. Acceptance of guideline recommendations and perceived implementation of coronary heart disease prevention among primary care physicians in five European countries: the Reassessing European Attitudes about Cardiovascular Treatment (REACT) survey. Fam Pract. 2002;19:596-604.

[10] de Abreu D, Guessous I, Vaucher J, Preisig M, Waeber G, Vollenweider P, et al. Low compliance with dietary recommendations for food intake among adults. Clin Nutr. 2013;32:783-8.

[11] de Abreu D, Guessous I, Gaspoz JM, Marques-Vidal P. Compliance with the Swiss Society for Nutrition's dietary recommendations in the population of Geneva, Switzerland: a 10-year trend study (1999-2009). J Acad Nutr Diet. 2014;114:774-80.

[12] Firmann M, Mayor V, Vidal PM, Bochud M, Pecoud A, Hayoz D, et al. The CoLaus study: a population-based study to investigate the epidemiology and genetic determinants of cardiovascular risk factors and metabolic syndrome. BMC Cardiovasc Disord. 2008;8:6.

[13] Marques-Vidal P, Bochud M, Bastardot F, von Känel R, Aubry J-M, Gaspoz J-M, et al. Assessing the associations between mental disorders, cardiovascular risk factors, and cardiovascular disease : the CoLaus/PsyCoLaus study. . Raisons de Santé. Lausanne, Switzerland: Institut universitaire de médecine sociale et préventive; 2011. p. 28.

[14] Canton de Vaud. Population totale selon l'origine, 1979-2014. In: Statistiques Vaud, editor. Lausanne, Switzerland: Département des finances et des relations extérieures,; 2015. 
[15] Canton de Vaud. Population résidante permanente âgée de 15 ans et plus selon la langue principale et le bilinguisme, 2010-2013. In: Statistiques Vaud, editor. Lausanne, Switzerland: Département des finances et des relations extérieures,; 2015.

[16] Morabia A, Bernstein M, Heritier S, Ylli A. Community-based surveillance of cardiovascular risk factors in Geneva: methods, resulting distributions, and comparisons with other populations. Prev Med. 1997;26:311-9.

[17] Bernstein L, Huot I, Morabia A. Amélioration des performances d'un questionnaire alimentaire semiquantitatif comparé à un rappel des 24 heures. Santé Publique. 1995;7:403-13.

[18] Marques-Vidal P, Ross A, Wynn E, Rezzi S, Paccaud F, Decarli B. Reproducibility and relative validity of a food-frequency questionnaire for French-speaking Swiss adults. Food Nutr Res. 2011;55.

[19] Swiss Society of Nutrition. Substances nutritives. In: Swiss Society of Nutrition, editor.: Swiss Society of Nutrition,; 2011.

[20] Swiss Society of Nutrition. La pyramide alimentaire suisse. In: Nutrition SSo, editor.2011.

[21] Walter P, Infanger E, Mühlemann P. Food Pyramid of the Swiss Society for Nutrition. Ann Nutr Metab. 2007;51:15-20.

[22] Perk J, De Backer G, Gohlke H, Graham I, Reiner Z, Verschuren M, et al. European Guidelines on cardiovascular disease prevention in clinical practice (version 2012). The Fifth Joint Task Force of the European Society of Cardiology and Other Societies on Cardiovascular Disease Prevention in Clinical Practice (constituted by representatives of nine societies and by invited experts). Eur Heart J. 2012;33:1635-701.

[23] Ley SH, Hamdy O, Mohan V, Hu FB. Prevention and management of type 2 diabetes: dietary components and nutritional strategies. Lancet. 2014;383:1999-2007.

[24] Evert AB, Boucher JL, Cypress M, Dunbar SA, Franz MJ, Mayer-Davis EJ, et al. Nutrition therapy recommendations for the management of adults with diabetes. Diabetes Care. 2014;37 Suppl 1:S12043. 
[25] Iqbal R, Ajayan K, Bharathi AV, Zhang X, Islam S, Soman CR, et al. Refinement and validation of an FFQ developed to estimate macro- and micronutrient intakes in a south Indian population. Public Health Nutr. 2009;12:12-8.

[26] European Association for Cardiovascular P, Rehabilitation, Reiner Z, Catapano AL, De Backer G, Graham I, et al. ESC/EAS Guidelines for the management of dyslipidaemias: the Task Force for the management of dyslipidaemias of the European Society of Cardiology (ESC) and the European Atherosclerosis Society (EAS). Eur Heart J. 2011;32:1769-818.

[27] Amouyel P, Farnier M, Lyon G, Siest G, Mortier N, Amiot N, et al. [Management of dyslipidemias diagnosed in general practice in France--The PRAGMA Study]. Arch Mal Coeur Vaiss. 2001;94:1045-53.

[28] Upadhyay UD, Waddell EN, Young S, Kerker BD, Berger M, Matte T, et al. Prevalence, awareness, treatment, and control of high LDL cholesterol in New York City, 2004. Prev Chronic Dis. 2010;7:A61.

[29] Guallar-Castillon P, Gil-Montero M, Leon-Munoz LM, Graciani A, Bayan-Bravo A, Taboada JM, et al. Magnitude and management of hypercholesterolemia in the adult population of Spain, 2008-2010: The ENRICA Study. Rev Esp Cardiol (Engl Ed). 2012;65:551-8.

[30] Fournier T, Bruckert E, Czernichow S, Paulmyer A, Poulain JP. The THEMA study: a sociodemographic survey of hypercholesterolaemic individuals. J Hum Nutr Diet. 2011;24:572-81.

[31] Schoch AH, Raynor HA. Social desirability, not dietary restraint, is related to accuracy of reported dietary intake of a laboratory meal in females during a 24-hour recall. Eat Behav. 2012;13:78-81.

[32] Kulick D, Langer RD, Ashley JM, Gans KM, Schlauch K, Feller C. Live well: a practical and effective low-intensity dietary counseling intervention for use in primary care patients with dyslipidemia--a randomized controlled pilot trial. BMC Fam Pract. 2013;14:59.

[33] Hu FB, Willett WC. Optimal diets for prevention of coronary heart disease. JAMA. 2002;288:256978. 
[34] Henson S, Blandon J, Cranfield J, Herath D. Understanding the propensity of consumers to comply with dietary guidelines directed at heart health. Appetite. 2010;54:52-61.

[35] Goulet J, Nadeau G, Lapointe A, Lamarche B, Lemieux S. Validity and reproducibility of an interviewer-administered food frequency questionnaire for healthy French-Canadian men and women. Nutr J. 2004;3:13. 


\section{Tables}

Table 1: Characteristics of the sample, according to diagnosis and dietary management of dyslipidemia.

\begin{tabular}{|c|c|c|c|c|}
\hline & \multirow[t]{2}{*}{ Not aware } & \multicolumn{2}{|c|}{ Aware } & \multirow[t]{2}{*}{ P-value } \\
\hline & & No diet & Diet & \\
\hline $\mathbf{N}$ & 2919 & 917 & 453 & \\
\hline Women $(\%)$ & $1645(56.4)$ & $387(42.2)$ & $242(53.4)$ & $<0.001$ \\
\hline Age (years) & $56.1 \pm 10.3$ & $59.3 \pm 10.2$ & $63.3 \pm 9.7$ & $<0.001$ \\
\hline \multicolumn{5}{|l|}{ Age groups } \\
\hline$[40-45[$ & $998(34.2)$ & $196(21.4)$ & $49(10.8)$ & \\
\hline$[50-60[$ & $904(31.0)$ & $287(31.3)$ & $109(24.1)$ & $<0.001$ \\
\hline$[60-70[$ & $699(24.0)$ & $274(29.9)$ & $173(38.2)$ & \\
\hline$[70+$ & $998(34.2)$ & $196(21.4)$ & $49(10.8)$ & \\
\hline \multicolumn{5}{|l|}{ Marital status } \\
\hline Alone & $1241(42.5)$ & $366(39.9)$ & $176(38.9)$ & 0.18 \\
\hline In couple & $1678(57.5)$ & $551(60.1)$ & $277(61.2)$ & \\
\hline \multicolumn{5}{|l|}{ Education } \\
\hline High & $686(23.5)$ & $206(22.5)$ & $69(15.2)$ & \\
\hline Middle & $824(28.2)$ & $212(23.1)$ & $110(24.3)$ & $<0.001$ \\
\hline Low & 1409 (48.3) & $499(54.4)$ & $274(60.5)$ & \\
\hline \multicolumn{5}{|l|}{ Smoking } \\
\hline Never & $1238(42.4)$ & $348(38.0)$ & $188(41.5)$ & \\
\hline Former & $1074(36.8)$ & $377(41.1)$ & $193(42.6)$ & 0.007 \\
\hline Current & $607(20.8)$ & $192(20.9)$ & $72(15.9)$ & \\
\hline History of CVD & $68(2.3)$ & $92(10.0)$ & $67(14.8)$ & $<0.001$ \\
\hline History of diabetes & $119(4.1)$ & $116(12.7)$ & $64(14.1)$ & $<0.001$ \\
\hline Hypolipidemic drug treatment $\S$ & - & $586(14.2)$ & $352(38.0)$ & $<0.001$ \\
\hline BMI $\left(\mathrm{kg} / \mathrm{m}^{2}\right)$ & $25.6 \pm 4.5$ & $27.1 \pm 4.5$ & $27.0 \pm 4.5$ & $<0.001$ \\
\hline \multicolumn{5}{|l|}{ BMI categories } \\
\hline Normal & $1448(49.6)$ & $310(33.8)$ & $156(34.4)$ & \\
\hline Overweight & $1063(36.4)$ & $411(44.8)$ & $199(43.9)$ & $<0.001$ \\
\hline Obese & $408(14.0)$ & $196(21.4)$ & $98(21.6)$ & \\
\hline
\end{tabular}


Results are expressed as number of subjects and (column percentage). BMI, body mass index; CVD; cardiovascular disease. § among participants aware of dyslipidemia only. Statistical analysis by chi-square or analysis of variance. 
Table 2: Food consumption according to diagnosis and dietary management of dyslipidemia.

\begin{tabular}{|c|c|c|c|c|c|}
\hline & \multirow[t]{2}{*}{ Not aware } & \multicolumn{2}{|c|}{ Aware } & \multicolumn{2}{|c|}{ P-value } \\
\hline & & No diet & Diet & Unadj. & Adj. $\S$ \\
\hline $\mathbf{N}$ & 2919 & 917 & 453 & & \\
\hline \multicolumn{6}{|l|}{ Foods } \\
\hline Fruits / day & $2.1 \pm 1.7^{\mathrm{a}}$ & $1.9 \pm 1.7^{\mathrm{a}}$ & $2.5 \pm 1.9^{b}$ & $<0.001$ & $<0.001$ \\
\hline Vegetables / day & $1.6 \pm 1.0^{\mathrm{a}}$ & $1.4 \pm 0.9^{b}$ & $1.6 \pm 1.0^{\mathrm{a}}$ & $<0.001$ & $<0.001$ \\
\hline Dairy products / day & $1.4 \pm 1.1$ & $1.3 \pm 1.2$ & $1.5 \pm 1.2$ & 0.05 & 0.16 \\
\hline Bread \& cereals / day & $1.6 \pm 1.0$ & $1.5 \pm 1.0$ & $1.7 \pm 1.0$ & 0.053 & 0.20 \\
\hline Pastries / day & $0.9 \pm 0.8$ & $0.9 \pm 0.8$ & $0.9 \pm 0.8$ & 0.74 & 0.78 \\
\hline Meat / week & $4.8 \pm 2.9^{\mathrm{a}, \mathrm{b}}$ & $5.2 \pm 2.9^{\mathrm{a}}$ & $4.5 \pm 2.7^{b}$ & $<0.001$ & 0.002 \\
\hline Fish $\uparrow /$ week & $1.7 \pm 1.6^{\mathrm{a}}$ & $1.6 \pm 1.1^{\mathrm{a}}$ & $1.9 \pm 1.4^{b}$ & 0.002 & $<0.001$ \\
\hline Fresh fish / week & $1.1 \pm 1.0^{\mathrm{a}}$ & $1.0 \pm 0.8^{\mathrm{a}}$ & $1.2 \pm 0.9^{b}$ & $<0.001$ & $<0.001$ \\
\hline \multicolumn{6}{|l|}{ Energy and nutrients } \\
\hline TEI, w/alcohol (kcal/day) & $1868 \pm 634$ & $1899 \pm 645$ & $1843 \pm 618$ & 0.27 & 0.86 \\
\hline TEI, wo/alcohol $(\mathrm{kcal} / \mathrm{d})$ & $1792 \pm 616$ & $1798 \pm 619$ & $1762 \pm 597$ & 0.57 & 0.67 \\
\hline Total protein $(\% \mathrm{E})$ & $16.0 \pm 3.3$ & $16.3 \pm 3.3$ & $15.7 \pm 3.2$ & 0.005 & 0.07 \\
\hline Animal (\%P) & $68.3 \pm 10.8^{\mathrm{a}, \mathrm{b}}$ & $69.3 \pm 10.8^{a}$ & $66.8 \pm 11.3^{b}$ & $<0.001$ & 0.006 \\
\hline Total carbohydrate $(\% \mathrm{E})$ & $48.0 \pm 8.3^{\mathrm{a}}$ & $47.1 \pm 8.3^{\mathrm{a}}$ & $50.1 \pm 8.6^{b}$ & $<0.001$ & $<0.001$ \\
\hline Simple (\%C) & $48.6 \pm 14.0^{\mathrm{a}}$ & $47.1 \pm 14.2^{\mathrm{a}}$ & $50.6 \pm 14.0^{b}$ & $<0.001$ & 0.007 \\
\hline Total fat $(\% \mathrm{E})$ & $36.0 \pm 7.0^{\mathrm{a}}$ & $36.6 \pm 7.0^{\mathrm{a}}$ & $34.2 \pm 7.4^{b}$ & $<0.001$ & $<0.001$ \\
\hline SFA $(\% \mathrm{~F})$ & $37.1 \pm 6.0^{\mathrm{a}}$ & $37.8 \pm 5.7^{a}$ & $35.1 \pm 6.2^{b}$ & $<0.001$ & $<0.001$ \\
\hline MUFA (\%F) & $39.7 \pm 4.6^{\mathrm{a}}$ & $39.4 \pm 4.3^{\mathrm{a}}$ & $39.9 \pm 5.4^{b}$ & 0.04 & 0.01 \\
\hline PUFA $(\% F)$ & $14.3 \pm 3.9^{a}$ & $14.2 \pm 4.1^{\mathrm{a}}$ & $15.6 \pm 4.3^{b}$ & $<0.001$ & $<0.001$ \\
\hline Fibre (g/day) & $16.4 \pm 8.6^{\mathrm{a}}$ & $15.7 \pm 8.7^{\mathrm{a}}$ & $18.0 \pm 9.0^{b}$ & $<0.001$ & $<0.001$ \\
\hline Cholesterol (mg/day) & $309 \pm 146^{\mathrm{a}}$ & $316 \pm 138^{a}$ & $273 \pm 127^{b}$ & $<0.001$ & $<0.001$ \\
\hline Alcohol (g/day) & $10 \pm 14^{\mathrm{a}}$ & $13 \pm 18^{\mathrm{b}}$ & $10 \pm 17^{\mathrm{a}, \mathrm{b}}$ & $<0.001$ & 0.01 \\
\hline Alcohol (g/day) $\div$ & $12 \pm 15^{\mathrm{a}}$ & $15 \pm 19^{b}$ & $13 \pm 18^{\mathrm{a}, \mathrm{b}}$ & $<0.001$ & 0.008 \\
\hline
\end{tabular}

TEI, total energy intake; \%E, as percentage of total energy intake; \% $\mathrm{P}$, as percentage of total protein intake; $\% \mathrm{C}$, as percentage of total carbohydrate intake; $\% \mathrm{~F}$, as percentage of total fat intake; SFA, saturated fatty acids; MUFA, monounsaturated fatty acids; PUFA, polyunsaturated fatty acids. Results are expressed as mean \pm standard deviation. Statistical analysis by ANOVA or Kruskall-Wallis test (for 
alcohol). NA, not assessable. $§$ adjusted for gender, age (continuous), body mass index (normal, overweight, obese), education (low, middle, high), smoking (never, former, current) and personal history of cardiovascular disease (yes/no) or diabetes (yes/no) with post-hoc pairwise comparisons using Scheffe's method; values with different subscripts are significantly different at $p<0.05$. $\dagger$, including fried and canned fish; $\$$, drinkers only. 
Table 3: Bivariate and multivariable analysis of compliance with dietary recommendations according to diagnosis and dietary management of dyslipidemia.

\begin{tabular}{|c|c|c|c|c|c|c|}
\hline & \multirow[t]{2}{*}{ Not aware } & \multicolumn{2}{|c|}{ Aware } & \multirow{2}{*}{\multicolumn{2}{|c|}{$\begin{array}{c}\text { Not } \\
\text { aware }\end{array}$}} & \multirow[b]{2}{*}{ No diet } \\
\hline & & No diet & Diet & & & \\
\hline Foods & 2919 & 917 & 453 & & & \\
\hline Fruits $\geq 2 /$ day & $1249(42.8)$ & $345(37.6)$ & $243(53.6)$ & $<0.001$ & 1 (ref.) & $0.83(0.71-0.98) *$ \\
\hline Vegetables $\geq 3 /$ day & $232(8.0)$ & $50(5.5)$ & $40(8.8)$ & 0.02 & 1 (ref.) & $0.68(0.49-0.95) *$ \\
\hline Dairy products $\geq 3$ /day & $260(8.9)$ & $70(7.6)$ & $44(9.7)$ & 0.36 & 1 (ref.) & $0.86(0.65-1.14)$ \\
\hline Meat $\leq 5 /$ week & $1766(60.5)$ & $510(55.6)$ & $296(65.3)$ & 0.001 & 1 (ref.) & $0.88(0.75-1.03)$ \\
\hline Fish $\geq 1 /$ week $\$$ & $1947(66.7)$ & $619(67.5)$ & $334(73.7)$ & 0.01 & 1 (ref.) & $1.05(0.89-1.23)$ \\
\hline Fish $\geq 1 /$ week $\mathbb{q}$ & $1167(40.0)$ & $346(37.7)$ & $224(49.5)$ & $<0.001$ & 1 (ref.) & $1.01(0.86-1.19)$ \\
\hline At least 3 recommendations $\$$ & $729(25.0)$ & $173(18.9)$ & $155(34.2)$ & $<0.001$ & 1 (ref.) & $0.73(0.60-0.89) * *$ \\
\hline At least 3 recommendations $\mathbb{I}$ & $527(18.1)$ & $125(13.6)$ & $125(27.6)$ & $<0.001$ & 1 (ref.) & $0.78(0.63-0.98) *$ \\
\hline \multicolumn{7}{|l|}{ Nutrients } \\
\hline Total fat $<30 \%$ TEI & $563(19.3)$ & $167(18.2)$ & $126(27.8)$ & $<0.001$ & 1 (ref.) & $0.94(0.77-1.15)$ \\
\hline SFA $<10 \%$ TEI & $473(16.2)$ & $121(13.2)$ & $135(29.8)$ & $<0.001$ & 1 (ref.) & $0.82(0.66-1.03)$ \\
\hline MUFA $>10 \%$ TEI & $2609(89.4)$ & $822(89.6)$ & $380(83.9)$ & 0.002 & 1 (ref.) & $1.08(0.84-1.39)$ \\
\hline PUFA $>10 \%$ TEI & $45(1.5)$ & $11(1.2)$ & $8(1.8)$ & 0.67 & 1 (ref.) & $0.68(0.34-1.35)$ \\
\hline Cholesterol $<300 \mathrm{mg} /$ day & $1608(55.1)$ & $483(52.7)$ & $301(66.5)$ & $<0.001$ & 1 (ref.) & $0.99(0.84-1.16)$ \\
\hline Fibre $>30 \mathrm{~g} /$ day & $239(8.2)$ & $83(9.1)$ & $43(9.5)$ & 0.52 & 1 (ref.) & $1.10(0.84-1.45)$ \\
\hline Moderate alcohol $\S$ & $2294(78.6)$ & $676(73.7)$ & $359(79.3)$ & 0.006 & 1 (ref.) & $0.82(0.69-0.99) *$ \\
\hline
\end{tabular}

TEI, total energy intake, excluding alcohol; SFA, saturated fat; MUFA, monounsaturated fat; PUFA, polyunsaturated fat. Results are expressed as number of participants (percentage) or as multivariate adjusted odds ratio and (95\% confidence interval). Statistical analysis by chi-square or logistic regression adjusting on gender, age ([40-50[, [50-60[, [60-70[ and [70+), body mass index (normal, overweight, obese), education (low, middle, high), smoking (never, former, current) and personal history of cardiovascular disease (yes/no) or diabetes (yes/no). $\$$ including canned and fried fish; $\mathbb{~} \mathbb{f}$ fresh fish only; defined as alcohol consumption $<20 \mathrm{~g} /$ day for men and $<10 \mathrm{~g} /$ day for women. $*, \mathrm{p}<0.05 ; * *, \mathrm{p}<0.01$; ***, $\mathrm{p}<0.001$. 